\title{
OUTCOME OF TYPE 1 TYMPANOPLASTY WITH AND WITHOUT THE USE OF TOPICAL NASAL STEROID: A COMPARATIVE STUDY FROM EASTERN NEPAL
}

\author{
Shah $R K^{1^{*}}$, Shrestha $K^{1}$, Sapkota $S^{1}$, Giri $S^{1}$
}

\section{Affiliation}

1. Lecturer, Department of Otorhinolaryngology, Birat Medical College \& Teaching Hospital. Biratnagar, Morang, Nepal.

\section{ARTICLE INFO \\ Article History}

(c) Authors retain copyright and grant the journal right of first publication with the work simultaneously licensed under Creative Commons Attribution License CC - BY 4.0 that allows others to share the work with an acknowledgment of the work's authorship and initial publication in this journal.

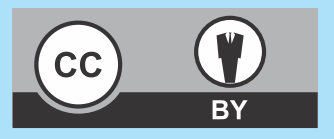

ORA 60

DOI: http://dx.doi.org/10.3126/bjhs.v3i1.19765

\author{
* Corresponding Author \\ Dr. Rajeev Kumar Shah \\ Lecturer \\ Department of Otorhinolaryngology \\ Birat Medical College \& Teaching Hospital \\ Biratnagar, Morang, Nepal. \\ E-mail: shahrajeev2001@gmail.com \\ https://orcid.org/0000-0003-2398-157X
}

\section{ABSTRACT \\ Introduction}

Chronic suppurative otitis media (CSOM) is the infection of the middle ear cleft. It is an important cause of preventable hearing loss.

\section{Objectives}

The primary objective of this study is to compare the surgery outcome in terms of graft uptake described as intact tympanic membrane or residual perforation of tympanic membrane in patients with use of levocetirizine tablet 5 milligram only and levocetirizine tablet 5 milligram with topical fluticasone 100 microgram nasal steroid spray. This study is also aimed to determine the hearing status before and after the surgery and to find out its association with graft intake.

\section{Methodology}

This prospective cross sectional study was conducted on patients diagnosed with chronic suppurative otitis media with medium to large central perforation of tympanic membrane in Birat Medical College Teaching Hospital during the period from 14 April 2015 to 13 April 2017. All the patients underwent type 1 tympanoplasty with placement of temporalis fascia under general anesthesia. After surgery, two equal groups were created with 40 patients in each group. One group received antibiotics, levocetirizine tablet and another group received antibiotics, levocetirizine tablet along with topical intranasal steroid spray from $1^{\text {st }}$ post operative day till $6 \mathrm{wks}$. All the patients were followed up on $5^{\text {th }}$ day, $7^{\text {th }}$ day and $42^{\text {nd }}$ day. On $42^{\text {nd }}$ day, status of tympanic membrane graft, post operative hearing assessment was done and compared between the two groups. Data were entered and analysed using Statistical Package For Social Sciences (SPSS) v21.

\section{Result}

There were 40 patients who received levocetirizine only starting from the first post operative day and 39 patients received levocetirizine and topical nasal steroid spray. Patients with intact tympanic membrane following surgery were $88.6 \%$ and remaining had residual perforation of tympanic membrane. Of the study participants $87.3 \%$ had improvement during post operative hearing assessment. $92.3 \%$ of the patients receiving levocetirizine and topical nasal steroid post surgery had intact tympanic membrane on otoscopic examination and there was a significant association with $\mathrm{p}$ value of 0.04

\section{Conclusion}

Combination therapy with topical intranasal steroid spray, antihistaminics and antibiotics is beneficial compared to antibiotics and antihistaminics in type 1 tympanoplasty in terms of graft intake and improvement in hearing.

\section{KEYWORDS}

Chronic suppurative otitis media, topical nasal steroid 


\section{INTRODUCTION}

Chronic suppurative otitis media (CSOM) is the infection of the middle ear cleft. This results as an initial episode of acute otitis media followed by a persistent discharge from the middle ear through a perforation in tympanic membrane. It is an important cause of preventable hearing loss, particularly in the developing world. ${ }^{1}$ It is common in both sexes and in all age groups. ${ }^{2}$ There are two types of CSOM mucosal and squamous type. The mucosal type can be treated surgically by tympanoplasty. The technique includes the manipulation of the tympanic membrane and eradication of disease from the middle ear cleft with or without reconstruction of ossicular chain., ${ }^{3,4}$ It is classified based on the placement of graft in relation to the remnant tympanic membrane as: ${ }^{4}$

a) Underlay technique: graft is placed medial to the mucosal layer.

b) Overlay technique: graft is placed lateral to the fibrous layer of tympanic membrane after elevating all squamous epithelium.

c) Interlay technique: graft is placed between the fibrous layer and the endothelial (mucosal) layer of the drum remnant.

In this study, post aural approach underlay technique was used for graft placement and graft was taken from temporalis fascia. The most commonly used graft in primary tympanoplasty with well aerated middle ears is temporalis fascia with success rate between $93 \%$ and $97 \%$. ${ }^{5,6}$

The primary objective of the present study is to compare the surgery results in terms of graft uptake described as intact tympanic membrane or residual perforation of tympanic membrane in patients with use of levocetirizine tablet 5 milligram only and levocetirizine tablet 5 milligram with topical fluticasone 100 microgram nasal steroid spray.

Topical intranasal steroid spray helps to improve the Eustachian tube dysfunction by reducing allergic and non allergic mucosal swelling with success rate ranging from 70 to $90 \%$. Combination therapy with antibiotics and intranasal steroids spray is beneficial than use of antibioitics alone especially in children. ${ }^{8}$

This study is also aimed to determine the hearing status before and after the surgery and to find out its association with graft intake.

As CSOM is common in developing countries especially in marignalised population, early identification of the disease and its timely treatment can reduce the unwanted sequale in the form of morbidity and hearing disability.

\section{METHODOLOGY}

This prospective cross sectional study was conducted in ENT department of Birat Medical College and Teaching Hospital from 14 April 2015 till 13 April 2017. Informed written consent was obtained from the participants and permission was obtained from the institute to carry out this study.
The inclusion criteria for the participants were (a) Age more than 10 years (b) Diagnosed case of chronic suppurative otitis media with medium sized central perforation. The following participants were excluded from the study (a) Age less than 10 years (b) Diagnosed case of chronic suppurative otitis media with marginal perforation, (c) Patient who had acute ear infection (active ear discharge, fever) and upper respiratory tract infection, (d) Patient who had history of diabetes, active tuberculosis, bleeding disorders and other immune suppressed condition; and (e) those who didn't consent to participate.

Relevant history and examination findings were noted with focus on duration of ear discharge, hearing status and other co morbid condition including diabetes, hypertension, and immune suppression. Otoscopic examination was done in all the patients and status of ear drum was identified and noted. Preoperative hearing assessment was done in all the patients by Pure Tone Audiometry. After ruling out all the exclusion criteria, all the preoperative investigation was sent and patients underwent underlay type 1 tympanoplasty. All the patients were operated by same surgeon, using same technique under general anesthesia. Temporalis fascia was used as a graft material in all the patients. During post operative period, starting from first post operative day, One group of patients were given antibiotics, levocetirizine 5 milligram tablet and another group of patients were given antibiotics, levocetirizine 5 milligram tablet and fluticasone nasal steroid spray 100 microgram 2 puff per nasal twice a day for 6 weeks. All the patients were followed on $5^{\text {th }}$ post operative day and status of wound was assessed. Again they were followed on 7th day and on $42^{\text {nd }}$ day. On $42^{\text {nd }}$ day, otoscopic examination was performed on all the patients and intake of graft was assessed on the basis of intact tympanic membrane or residual perforation of tympanic membrane. Post operative hearing assessment was also done in all the patients by Pure Tone Audiometry and categorized as improved, not improved or worsened hearing status when compared to pre-operative values.

All the findings were noted on semi standardized study proforma. The data thus obtained was entered into statistical software SPSS V21 and analyzed. For descriptive statistics, percentage, mean and standard deviation was calculated along with graphical and tabular presentation. Continuous variables with normal distribution were expressed as mean,_standard deviation and were compared using t-test.

\section{RESULT}

Initially equal number of participants $(n=40)$ were enrolled in both the groups. However one patient who was prescribed nasal steroid after the surgery didn't turn up for follow up. Hence, total number of cases in the present study is 79 of which $46.8 \%$ were male and $53.2 \%$ female. Mean age of presentation was $32.48 \pm 13.0$ years and mean hearing loss prior to surgery was $41.94 \pm 7.22$ decibel. (Table 1 ) 


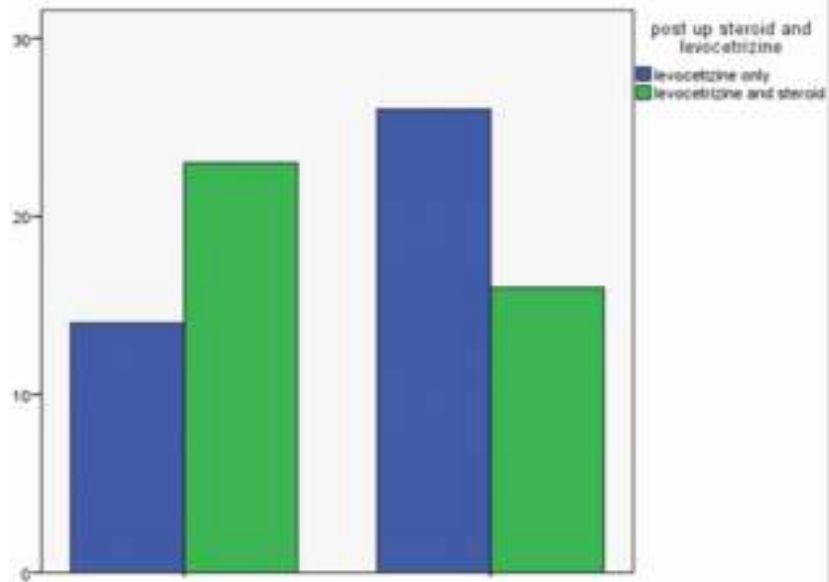

Figure 1: Bar diagram showing frequency of male and female patients receiving levocetrizine only and levoce tirizine with nasal steroid post operatively.

There were 40 patients who received levocetirizine only starting from the first post operative day and 39 patients received levocetirizine and topical nasal steroid spray. This was continued for 6 weeks. Frequency of male and female patients receiving levocetrizine only and levocetrizine with nasal steroid post operatively is shown in Figure 1 . There were 68 patients who came for follow up on $5^{\text {th }}$ day, 79 patients came on follow up on day 7 and 79 patients came on follow up on day 42 . Patients with intact tympanic membrane following surgery were $88.6 \%$ and remaining had residual perforation of tympanic membrane. Of the study participants $87.3 \%$ had improvement during post operative hearing assessment. (Table 1 )

Table 1: Description of general characteristics of patients Characteristics Frequency $(\mathrm{N}=79)$

\begin{tabular}{|c|c|}
\hline Mean age (in years) & $32.48 \pm 13.0$ \\
\hline Mean preoperative hearing loss (decibel) & $41.94 \pm 7.22$ \\
\hline \multicolumn{2}{|l|}{ Study groups } \\
\hline Receiving levocetrizine only & $40(50.6 \%)$ \\
\hline Receiving levocetrizine and nasal steroid & $39(49.4 \%)$ \\
\hline \multicolumn{2}{|l|}{ Post operative status of tympanic membrane } \\
\hline Intact & $70(88.6 \%)$ \\
\hline Residual perforation & $9(11.4 \%)$ \\
\hline \multicolumn{2}{|l|}{ Post operative surgical outcome } \\
\hline 1. Post surgery hearing improved & $69(87.3 \%)$ \\
\hline 2. Post operative hearing not improved & $9(11.4 \%)$ \\
\hline 3. Post operative hearing worsened & $1(1.1 \%)$ \\
\hline
\end{tabular}

On $6^{\text {th }}$ week follow up, $48.5 \%$ of patients with intact tympanic membrane post surgery had improvement in post operative hearing assessment. Among them 33 patients received only levocetrizine and 35 patients received levocetrizine plus nasal steroid. (Table 2) $92.3 \%$ of the patients receiving levocetirizine and topical nasal steroid post surgery had intact tympanic membrane on otoscopic examination and there was a significant association with $p$ value of 0.04 (Table 2 )

\begin{tabular}{|c|c|c|c|c|}
\hline $\begin{array}{l}\text { Post op } \\
\text { hearing } \\
\text { assessment }\end{array}$ & $\begin{array}{l}\text { Graft } \\
\text { intake }\end{array}$ & $\begin{array}{l}\text { Levocetrizine } \\
\text { only (N\%) }\end{array}$ & $\begin{array}{l}\text { Levocetrizine } \\
\text { plus nasal } \\
\text { steroid (N\%) }\end{array}$ & p-value \\
\hline \multirow[t]{2}{*}{ Improved } & Intact & 33 (82.50\%) & 35 (89.74\%) & \multirow{6}{*}{0.04} \\
\hline & $\begin{array}{l}\text { Residual } \\
\text { perforation }\end{array}$ & $1(2.50 \%)$ & $0(0 \%)$ & \\
\hline \multirow{2}{*}{$\begin{array}{l}\text { Not } \\
\text { improved }\end{array}$} & Intact & $1(2.50 \%)$ & $1(2.56 \%)$ & \\
\hline & $\begin{array}{l}\text { Residual } \\
\text { Perforation }\end{array}$ & $5(12.50 \%)$ & $2(5.13 \%)$ & \\
\hline Worsened & $\begin{array}{l}\text { Residual } \\
\text { Perforation }\end{array}$ & $0(0 \%)$ & $1(2.56 \%)$ & \\
\hline \multicolumn{2}{|l|}{ Total } & 40 (100\%) & 39 (100\%) & \\
\hline
\end{tabular}

$86.07 \%$ of the patients had improvement in hearing post surgery with intact tympanic membrane and there was a significant association with p value of 0.025 . (Table 3 )

Table 3: Association between post operative graft intake with assessment of hearing after surgery

\begin{tabular}{|l|c|c|l|l|}
\hline Variables & $\begin{array}{l}\text { Hearing } \\
\text { improved } \\
\text { (N\%) }\end{array}$ & $\begin{array}{l}\text { Hearing not } \\
\text { improved } \\
\text { (N\%) }\end{array}$ & $\begin{array}{l}\text { Hearing } \\
\text { worsened } \\
\text { (N\%) }\end{array}$ & P-value \\
\hline $\begin{array}{l}\text { Intact } \\
\text { tympanic } \\
\text { membrane }\end{array}$ & $68(86.07 \%)$ & $2(2.53 \%)$ & $0(0 \%)$ & \\
\hline $\begin{array}{l}\text { Residual } \\
\text { tympanic } \\
\text { membrane }\end{array}$ & $1(1.27 \%)$ & $7(8.86 \%)$ & $1(1.27 \%)$ & \\
\hline Total & $69(87.34 \%)$ & $9(11.39 \%)$ & $1(1.27 \%)$ & \\
\hline
\end{tabular}

\section{DISCUSSION}

The prevalence of otitis media in the school children in Nepal was found to be ranging from 5.4 to $13.2 \%$ and those with hearing loss comprised $12.47 \%$. Prevalence was much higher in children than adults, particularly belonging to lower economic strata. ${ }^{9-12}$

Tympanoplasty is the operative procedure done in patients with chronic otitis media to restore middle ear function and remove infection. ${ }^{3}$ The technique and approach for this procedure is chosen by the surgeon, ${ }^{13}$ however post auricular approach is much favored as it leaves less visible scar.

Studies have shown that use of intranasal topical steroid is beneficial than use of only antibiotic in Eustachian tube dysfunction which was comparable to our study. ${ }^{14,15}$

In the present study underlay technique was used as it is ideal technique in terms of visualization, less time consuming and easy to perform. The other advantage of this technique is the correct level of healing of the drum in respect to the annulus and ossicles. ${ }^{3}$

There was remarkable postoperative hearing improvement and closure of perforation in 81 of 100 dry eared patients 
with type 1 tympanoplasty with internal graft technique (underlay). ${ }^{16}$

It has been observed that age, gender or size of the perforation had no significant effect on the outcome of surgery. ${ }^{16}$ The condition of the ear whether dry or wet (suppurative) also doesn't play a role in outcome of surgery as satisfying results were noted in terms of graft uptake and post operative hearing improvement in both dry and wet cases. $^{17}$

\section{CONCLUSION}

Combination therapy with topical intranasal steroid spray, antihistaminics and antibiotics during post operative period after Type 1 tympanoplasty for medium to large central perforation of tympanic membrane is beneficial compared to antibiotics and antihistaminics only in terms of graft intake and improvement in hearing.

\section{RECOMMENDATION}

This study, about outcome of Type 1 Tympanoplasty, with and without the use of topical nasal steroid is one of its kind conducted in Nepal. RCT and multicentric study has to be conducted to know about the exact beneficial effect of the use of topical nasal steroid following tympanoplasty.

\section{LIMITATIONS OF THE STUDY}

The research was conducted only in a small group of population with medium to large sized central perforation attending the ENT OPD. Similar kind of study has to be conducted in all the cases of mucosal disease in a larger group of population to know the exact beneficial effect of topical nasal steroid post surgery.

\section{ACKNOWLEDGMENT}

The authors would like to thank Dr. Alok Atreya, Assistant Professor, Department of Forensic Medicine, Devdaha Medical College \& Research Institute, Rupandehi, Nepal and Dr. Sangya Gyawali, for their help in stastical analysis and review of this manuscript. The authors would also like to acknowledge the participants without whom the study would not have been possible.

\section{CONFLICT OF INTEREST}

None

\section{REFERENCES}

1. WHO. Chronic suppurative otitis media - Burden of Illness and Management Options. WHO Libr Cat Data [Internet]. 2004;84. Available from: http://www.who.int/pbd/publications/ Chronicsuppurativeotitis_media.pdf.

2. Ambani KP, Gangwani RW, Bhavya BM, Vakharia SD, Katarkar AU. A comparative study between fat myringoplasty and temporalis fascia tympanoplasty in moderate to large central perforation of pars tensa of tympanic membrane. Int J Otorhinolaryngol Head Neck Surg. 2017;3(4):997-1001.

3. Sarkar S. A review on the history of tympanoplasty. Indian J Otolaryngol Head Neck Surg. 2013;65(December):S455-60. DOI: 10.1007/s12070-012-0534-5.

4. Patil BC, Misale PR, Mane RS, Mohite AA. Outcome of Interlay Grafting in Type 1 Tympanoplasty for Large Central Perforation. Indian J Otolaryngol Head Neck Surg. 2014;66(4):418-24. DOI: 10.1007/s12070-014-0741-3.

5. Mohamad SH, Khan I, Hussain SSM. Is cartilage tympanoplasty more effective than fascia tympanoplasty? A systematic review. Otol Neurotol. 2012;33(5):699-705. DOI: 10.1097/MAO.0b013e3 $18254 \mathrm{fbc} 2$.

6. Lee JC, Lee SR, Nam JK, Lee TH, Kwon JK. Comparison of different grafting techniques in type i tympanoplasty in cases of significant middle ear granulation. Otol Neurotol. 2012;33(4):586-90. DOI: 10.1097/MAO.0b013e31824b78ba.

7. Rashid M. Rationale and feasibility of intranasal delivery of drugs to the eustachian tube orifice. Curr Allergy Asthma Rep. 2012;12(6): 541-6. DOI: 10.1007/s11882-012-0310-3.

8. Kalish L, Snidvongs K, Sivasubramaniam R, Cope D, Harvey RJ. Topical steroids for nasal polyps. Cochrane database Syst Rev [Internet]. 2012;12(12):CD006549. DOI: 10.1002/14651858. CD006549. pub2.

9. Maharjan M, Bhandari S, Singh I, Mishra SC. Prevalence of otitis media in school going children in Eastern Nepal. Kathmandu Univ Med J (KUMJ). 2006;4(4):479-82. PMID: 18603958.

10. P, Sinha BK, Pokharel Adhikari NR, Kharel B, Aryal R, Ma J. Prevalence of chronic suppurative otitis media in school children of Kathmandu district. J Institute Med. 2007;29(3).

11. Rijal AS, Joshi RR, Regmi S, Malla NS, Dhungana A, Jha AK, Rijal JP. Ear diseases in children presenting at Nepal Medical College Teaching Hospital. Nepal Med Coll J. 2011;13(3):164-8. PMID: 22808806.

12. Adhikari P. Pattern of ear diseases in rural school children: experiences of free health camps in Nepal. Int J Pediatr Otorhinolaryngol. 2009;73(9):1278-80. DOI: 10.1016/j.ijporl. 2009.05.020.

13. Cummings CW. Otolaryngology Head \& Neck Surgery.5th ed. USA: Mosby; 2010.

14. Elies W. Topical steroids in the treatment of mucosal swelling of the nasal cavity. J Chemother. 1997;6:31-4. DOI: 10.1001/jama. 298.21.2487.

15. ThomasC,SimpsonS,ButlerC,vanderVoort. J.Topical nasal steroids for hearing loss associated with otitis media with effusion in children. J.Oralor Cochrane Database Syst Rev. 2006;3CD001935.

16. Shaikh AA, Onali M AS, Shaikh SM, Rafi T. Outcome of Tympanoplasty Type - I by Underlay Technique. JLUMHS 2009; 08(01):80-4.

17. Naderpour M, Shahidi N, Hemmatjoo T. Comparison of tympanoplasty results in dry and wet ears. Iran J Otorhinolaryngol. 2016;28(3):209-14. 